\title{
The Effect of Spark Timing and Negative Valve Overlap on Spark Assisted Compression Ignition Combustion Heat Release Rate
}

\author{
Robert J. Middleton ${ }^{\mathrm{a}, *}$, Laura K. Manofsky Olesky ${ }^{\mathrm{a}}$, George A. Lavoie ${ }^{\mathrm{a}}$, Margaret S. Wooldridge ${ }^{\mathrm{a}}$, \\ Dennis N. Assanis ${ }^{\mathrm{b}}$, Jason B. Martz ${ }^{\mathrm{a}}$ \\ ${ }^{a}$ University of Michigan, Mechanical Engineering Department, 1231 Beal Avenue, Ann Arbor, MI, 48109 \\ ${ }^{b}$ Stony Brook University, Stony Brook, NY, 11794
}

\section{Corresponding Author:}

Robert J. Middleton

W.E. Lay Automotive Laboratory

1231 Beal Avenue

Ann Arbor, MI 48109-2121

Tel: (734) 647-1409

Fax: (734) 764-4256

Email: rjmidd@umich.edu

Colloquium: IC Engine and Gas Turbine Combustion

Total paper length $=5882.28$ words $($ Method 1$)$

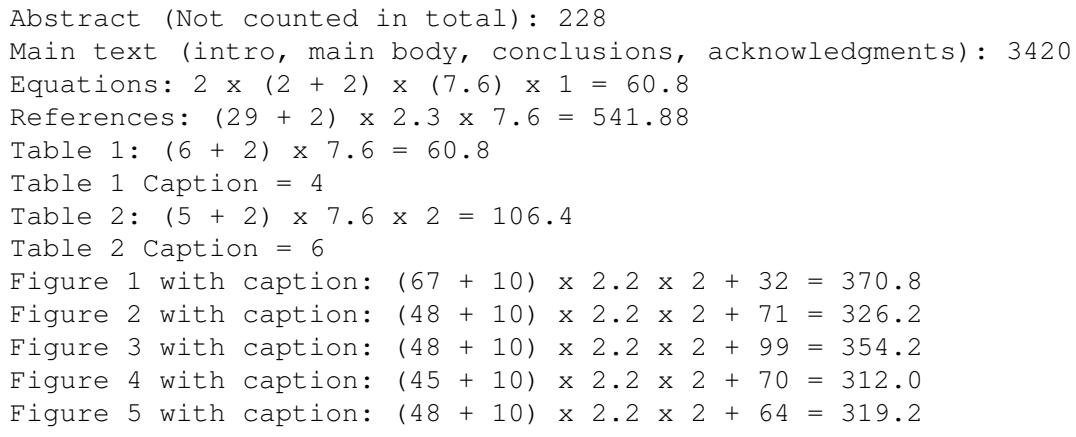

\footnotetext{
*Corresponding author

Email address: r jmidd@umich.edu ( Robert J. Middleton )
} 


\begin{abstract}
Spark assisted compression ignition (SACI) combustion is capable of partially decoupling combustion phasing from peak heat release rate, overcoming one of the major challenges associated with low temperature combustion. Experimental SACI studies have shown that for a given combustion phasing, peak heat release rate can be modulated by trading the fraction of the fresh charge consumed by flame propagation with the fraction consumed by auto-ignition. The chemical and physical mechanisms controlling the changes in heat release rate are not well known. The current work uses computational simulation to explore these modes through the combined control of spark timing and charge temperature via changes in negative valve overlap. Open cycle CFD simulation results are compared with experimental data to validate a newly developed SACI model, and used to gain insight into the processes governing combustion behavior. The simulations predict a $43 \%$ reduction in the peak rate of heat release with increasing spark advance, while the unburned charge mass at the time of auto-ignition decreases by only $23 \%$. Detailed analysis of the end-gas thermodynamic state prior to auto-ignition shows as spark is advanced, the end-gas thermal and compositional distributions vary with the fraction of the charge consumed by the flame. The reduction in the rate of peak rate of heat release during the auto-ignition process is therefore a function of both the mass of the end-gas and the end-gas reactivity.
\end{abstract}




\section{Introduction}

High thermal efficiency with low emissions has been successfully demonstrated using homogeneous charge compression ignition (HCCI) combustion [1-3]. However, it is difficult to decouple HCCI combustion phasing from peak rate of heat release [4]. High rates of heat release determine the high load limit for HCCI, which limits the use of HCCI to low load regimes [5-7]. These challenges have generated interest in alternative low temperature combustion modes such as Spark Assisted Compression Ignition (SACI) which expand the high load limit beyond the HCCI regime. Optical engine studies of SACI combustion have shown key features to be the presence of turbulent flames initiated at the spark plug, followed by end gas auto-ignition [8]. Laminar flame modeling predicts that flames can exist under the highly dilute conditions typical of SACI operation, provided that the unburned gas temperature is sufficiently high [9].

Recent experimental work has shown that the heat release rate of SACI combustion can be varied by controlling the relative contributions of the flame and auto-ignition combustion modes at constant combustion phasing $[10,11]$, where phasing is defined as crank angle of 50\% mass fraction burned (CA50). To adjust the balance between modes, the temperature at intake valve closing $\left(T_{\mathrm{IVC}}\right)$ and spark timing were adjusted simultaneously. For a given combustion phasing, a higher $T_{\mathrm{IVC}}$ required less spark advance (and associated flame compression of the end-gas) to achieve the end-gas temperature required for auto-ignition. Using this strategy the peak heat release rate was reduced by $40 \%$ with a $75 \%$ reduction in ringing intensity and $20 \%$ reduction in estimated end-gas mass at autoignition, while maintaining thermal efficiency. While these studies demonstrated the potential of such strategies, the mechanism(s) affecting the peak heat release rates have not be identified or quantified. Such information will enable the development of SACI strategies to achieve a wider engine operating regime.

The primary objective of the present investigation was to better identify the physical processes governing the behavior of SACI combustion at constant phasing as the fraction of flame and auto-ignition heat release are varied. The 3D reacting CFD code KIVA-3V was used to replicate the experimentally observed behavior of decreasing peak heat release rates with simultaneously increasing spark advance and decreasing $T_{\mathrm{IVC}}$. Detailed analysis of the simulated end-gas states was performed to identify the factors responsible for the changes in the overall heat release rate. 


\section{Model Formulation and Configuration}

The modeling work conducted here is designed to understand the physical processes responsible for the experimental SACI behavior previously reported in detail by Olesky et al. [10]. In that study $T_{\text {IVC }}$ and spark timing were simultaneously varied to maintain combustion phasing while manipulating the peak rate of heat release. Experiments were conducted in a single cylinder research engine unthrottled at atmospheric pressure, with constant fuel injection of $19 \mathrm{mg} /$ stroke resulting in $\approx 6.5 \mathrm{bar} \mathrm{IMEP}_{\mathrm{n}}$ and $\approx 42 \%$ net thermal efficiency. Model parameters and inputs are configured to match the experiment wherever possible, with engine geometry provided in Table 1 and operating conditions in Table 2.

Simulations of SACI combustion were conducted using the 3D CFD code KIVA-3V [12]. Turbulent flame propagation was simulated using the Coherent Flamelet model (CF) [13, 14], while detailed chemistry was simulated using the fully coupled Multi-Zone approach (MZ) [15]. A detailed description of the complete CFMZ model formulation is provided elsewhere [16, 17].

The CFMZ model is designed for use with detailed chemistry, solving two transport equations for every species in the chemical mechanism, one for the average composition of the cell and one for the unburned gas composition. Using this approach the end-gas mass consumed by the flame is modeled separately from the heat release associated with chemically controlled combustion. In each cell, fuel mass can be consumed entirely through flame propagation, auto-ignition, or a combination of the two modes, allowing the model to capture combustion in the HCCI, SACI, and SI combustion regimes.

The chemical mechanism used for end- and burned-gas chemistry in this work was the skeletal 215 species isooctane mechanism of Tham et al. [18], derived from the detailed mechanism of Curran et al. [19]. The spark event and flame kernel was tracked by lagrangian particles following the approach of Tan and Reitz [20], with the transition from purely laminar propagation to a laminar-turbulent phase and fully turbulent flame propagation modeled using the method of Boudier et al. [21]. A transport equation for the flame surface density $\Sigma$, the flame surface area per unit cell volume, was used to predict the surface area of the flame front [14]. Turbulent flame stretch was captured with a source term in the $\Sigma$ transport equation from the phenomenological Intermittent Turbulence Net Flame Stretch (ITNFS) model of Meneveau and Poinsot [13], which uses characteristic velocity and length scale information from the flow field and the flame to determine turbulent flame stretch and quenching. Laminar flame speed $\left(S_{L}\right)$ and thickness $(\delta)$ were estimated using correlations for $S_{L}$ and $\delta$ under the highly dilute conditions typical of SACI combustion [22, 23]. 
Open cycle simulations were conducted with the KIVA-CFMZ model using a 156,000 cell detailed 3D mesh corresponding to the metal engine of Olesky et al. [10, 24]. Characteristic cell dimensions near TDC were $1.1 \mathrm{~mm}$, with a maximum of $2.4 \mathrm{~mm}$. Simulation timesteps were determined implicitly and ranged between 2-10 $\mu$ s near combustion. Key geometric parameters of the fully flexible valve actuation (FFVA) direct-injected single cylinder research engine and computational mesh are provided in Table 1. The FFVA system provided independent control of lift, timing, and duration of each valve. Symmetric negative valve overlap (NVO) operation with fixed exhaust valve opening and intake valve closing timing was used to retain high temperature internal exhaust gas residuals to enable SACI combustion in the 12.4:1 compression ratio engine. The fuel in the experiments was 87 -octane research grade gasoline, injected during NVO at $330^{\circ}$ before top dead center (bTDC of combustion) to allow time for mixing prior to spark ignition. Fuel injection was modeled using the high-pressure swirl injector model of Chryssakis [25, 26], which accounts for both the primary and secondary atomization of fuel, as well as the transition of the initial pre-swirl spray with a solid cone to the steady state behavior of the main injection event with a hollow-cone structure. This model has previously been validated and showed good agreement with experimental PLIF measurements in an optical engine.

The KIVA simulations were configured based on the engine operating conditions of Olesky et al. [10], given in Table 2. All simulations were initialized at $-640^{\circ}$ bTDC of combustion, during the expansion stroke of the previous engine cycle, using estimates of the thermodynamic state of the experiments obtained from heat release analysis of the experimental data using the approach of Ortiz-Soto [27]. The initial turbulent flow field was imposed from a motored simulation of a complete $720^{\circ}$ engine cycle. To reduce the computational expense of the open cycle, the KIVA simulations used a non-reacting 5 species mechanism (isooctane, air, $\mathrm{CO}_{2}$ and $\mathrm{H}_{2} \mathrm{O}$ ) during the gas exchange process, including the trapping and recompression of residuals during NVO, fuel injection, and the intake of fresh charge. At IVC a restart file was written and the simulation re-initialized using the 215 species isooctane mechanism for detailed chemistry.

Boundary conditions in the intake and exhaust manifolds were imposed from the high speed manifold pressure measurements of the experiments. Due to differences in the locations of the mesh boundaries and manifold pressure measurements, there is uncertainty in the correct pressure at the valve seat at the instant the valve closes. To compensate for this uncertainty, the intake and exhaust manifold pressures used in the simulations were shifted with constant offsets of up to 0.1 bar to match the measured experimental data at $20^{\circ}$ bTDC of firing and TDC of NVO. Combustion chamber boundary temperatures of $475 \mathrm{~K}$ on the 
cylinder wall and firedeck and $505 \mathrm{~K}$ on the piston and intake valve surfaces are based on zero-dimensional cycle simulations in GT-Power, while the exhaust valves are set to $675 \mathrm{~K}$ based on the measurements of Omrane et al. [28].

The experiments were conducted with a constant intake temperature of $318 \mathrm{~K}$, while the simulations required increasing intake temperature to maintain combustion phasing as spark timing was retarded. Temperature adjustments of up to $15 \mathrm{~K}$ were applied to the model to adjust the phasing to match the experimental peak pressures. As a result the predicted equivalence ratio at IVC also shifted by up to $1.6 \%$ as indicated in Table 2.

\section{Comparison of KIVA Model Predictions with Experiments}

Figure 1 presents a comparison of the in-cylinder pressure of the simulation results with selected cycles from the experimental data for the three spark timing/NVO/T $T_{\mathrm{IVC}}$ conditions. Figure $1(\mathrm{~b})$ shows the 10 individual experimental cycles with peak pressures closest to those predicted by KIVA at each spark timing, selected from the 200 experimental cycles collected at each operating point. Individual engine cycles were used for model assessment rather than the 'mean' ensemble averaged experimental pressure, as the 'mean' cycle fails to represent the exact experimental behavior, due to the significant cyclic variability under SACI operation [24]. For both the model predictions and the experimental results, the cases with earlier spark advance and lower $T_{\mathrm{IVC}}$ have higher pressures at TDC compared to those with later spark at higher $T_{\mathrm{IVC}}$. The model predictions of peak pressure and rate of pressure rise are consistent with behavior observed in the individual experimental cycles shown in Figure 1(b), with the predicted location of peak pressure approximately $2^{\circ} \mathrm{CA}$ later than the experimental data, consistent with the longer ignition delay of the isooctane surrogate relative to gasoline.

Figure 2 presents the model results for the time histories for mass fraction burned, heat release rate, and mean unburned gas temperature for the three conditions in Table 2. The predicted mass fraction burned profiles were derived from the detailed accounting of each combustion mode available in KIVA. The overall mass fraction burned and the fraction due to flame front propagation are presented in Figure 2(a). The amount of burned mass produced by end-gas autoignition is omitted for clarity. The computations indicate a rapid transition from flame propagation, where the overall and flame front data overlap, to auto-ignition. The results also show the flame contribution to the combustion process is minimal beyond end-gas thermal runaway, consistent with detailed flame simulations exhibiting showing a rapid transition from flame to auto- 
ignition combustion at the time of end-gas ignition [9]. The predicted mass fraction burned by the flame increases with increasing spark advance, from $27 \%$ to $50 \%$, consistent with the experimentally reported decrease.

The heat release data (Figure 2(b)) show a significant decrease in the peak rate of heat release rate with increasing spark advance, consistent with the trends reported by Olesky et al. [10] for these conditions. Inflection points near $7^{\circ}$ ATDC correspond to the transition from the low rates of heat releases associated with flame propagation to the higher rates associated with bulk auto-ignition of the end-gas. Advancing spark timing from $25^{\circ}$ bTDC to $44^{\circ}$ bTDC resulted in a $43 \%$ reduction in the peak rate of heat release. However, the reduction in the end-gas mass prior to auto-ignition was only $23 \%$. Understanding the conditions in the end-gas responsible for the additional $20 \%$ reduction in heat release rate was the focus of the following analysis.

Figure 2(c) shows the model predictions of the mean end-gas temperature. The case with the most advanced spark timing and lowest $T_{\mathrm{IVC}}$ has the lowest unburned temperature at the time of spark, as well as the lowest temperature throughout the early stages of combustion. Dashed lines in the Figure indicate temperature predictions for simulations with the spark disabled and no flame propagation. Prior to autoignition of the end-gas, the difference between the solid and dashed lines correspond to compression heating of the end-gas by the flame. Additional flame propagation is associated with the lower $T_{\mathrm{IVC}}$ cases, and the simulation results show that approaching TDC, compression heating from flame propagation causes the predicted unburned temperatures to converge at approximately $1000 \mathrm{~K}$. Consistent with the fixed CA50 requirement of the experiments, the three simulation cases follow a common mean temperature rise from $1000 \mathrm{~K}$ to $1050 \mathrm{~K}$ and the transition to the high rate of temperature change corresponds to the onset of end-gas auto-ignition.

Due to the direct injection fueling strategy used, there is potential for both compositional stratification as well as temperature stratification. To better understand the state of the end-gas just prior to auto-ignition, the model predictions were analyzed on a cell-by-cell basis. The cells were sorted into bins of similar thermodynamic conditions and the mass in each bin was determined. Sorting was conducted by temperature and a variant of the non-product equivalence ratio $\varphi$, given as:

$$
\varphi=\frac{2 \mathrm{C}_{-\mathrm{CO}_{2}}^{\#}+\frac{1}{2} \mathrm{H}_{-\mathrm{H}_{2} \mathrm{O}}^{\#}}{\mathrm{O}_{-\mathrm{CO}_{2}-\mathrm{H}_{2} \mathrm{O}}^{\#}}
$$


where $\mathrm{C}_{-\mathrm{CO}_{2}}^{\#}, \mathrm{H}_{-\mathrm{H}_{2} \mathrm{O}}^{\#}$, and $\mathrm{O}_{-\mathrm{CO}_{2}-\mathrm{H}_{2} \mathrm{O}}^{\#}$ are the number of $\mathrm{C}, \mathrm{H}$, and $\mathrm{O}$ atoms not including those in the complete combustion products $\mathrm{CO}_{2}$ and $\mathrm{H}_{2} \mathrm{O}[15,23]$. For mixtures with zero reaction progress this definition is identical to the fuel $/ \mathrm{O}_{2}$ equivalence ratio. For a lean mixture $\varphi$ is less than 1.0, while for a stoichiometric mixture $\varphi=1.0$. Rich mixtures range from $\varphi>1.0$ to $\infty$, when the mixture is composed of pure fuel. To better capture this wide range of potential conditions a new equivalence ratio is adopted:

$$
\varphi^{*}=\left\{\begin{array}{rc}
\varphi & : \varphi \leq 1.0 \\
2-\frac{1}{\varphi} & : \varphi>1.0
\end{array}\right.
$$

where the range of $\varphi^{*}$ is 0.0 to 2.0 from pure air to pure fuel.

Figure 3 shows the mass-temperature and mass- $\varphi^{*}$ distributions of the end-gas at $5^{\circ}$ aTDC, which is immediately prior to auto-ignition at $7^{\circ}$ aTDC. The temperature distributions in Figure 3(a) show that the latest spark timing case exhibits notably higher masses on the high temperature side of the distribution, i.e. between $1050 \mathrm{~K}$ and $1125 \mathrm{~K}$, as well as slightly higher masses on the low temperature side, i.e. below $1000 \mathrm{~K}$, consistent with this case having the greatest total unburned mass at this crank angle. The overall shape of the temperature distribution shifts from roughly triangular for the earliest spark timing, to more rectangular with a broad top at the latest spark timing. Smaller differences in the mass-temperature distributions are also observed between the earliest and middle spark timing cases. Compositional distributions in Figure 3(b) show that the latest timing case also has more mass on the rich side of the distribution compared to the earlier timing cases, consistent with the shift in mean equivalence ratio present in the experiments and noted in Table 2. Figure 3(c) combines the results for thermal and compositional stratification into one figure by plotting the difference between the mass-state distributions of the $\mathrm{SA}=25^{\circ} \mathrm{bTDC}$ and $44^{\circ} \mathrm{bTDC}$ cases. The negative values are red and indicate the presence of more mass at a given $T$ and $\varphi^{*}$ in the $\mathrm{SA}=25^{\circ} \mathrm{bTDC}$ case, while positive values are blue and indicate more mass in the SA $=44^{\circ} \mathrm{bTDC}$ case. The results show the additional mass at high temperatures is co-located with the rich equivalence ratios in the late spark timing case. Higher temperatures and equivalence ratios will have lower ignition delays, as indicated in Figure 3(c) by dashed iso-lines calculated using the correlation of He et al. [29]. Similarly, higher temperatures and equivalence ratios closer to 1.1 will have higher laminar flame speeds, indicated in Figure 3(c) by dotted iso-lines calculated using the correlation of Middleton et al. [23]. These results suggest that advancing spark timing not only allows a larger fraction of the charge to be consumed by flame propagation, it also alters the distribution of thermodynamic states in the end gas 
remaining at auto-ignition toward conditions with lower reactivity.

Spatial distributions of end-gas temperature and the flame front location within the combustion chamber at $5^{\circ}$ aTDC are shown in Figure 4. Clip planes are indicated by black lines and colored by temperature, while the gray iso-surface for $\Sigma>1 \mathrm{~cm}^{-1}$ indicates the flame front location (gaps visible in the surface are formed as the flame interacts with the chamber walls). When viewed from above in Figures 4(a)-4(b), the additional flame propagation present in the $\mathrm{SA}=44^{\circ}$ bTDC case corresponds to the regions with the hottest unburned gas remaining in the $\mathrm{SA}=25^{\circ} \mathrm{bTDC}$ case, consistent with the previously noted changes to the high temperature side of the mass-temperature distribution in Figure 3. Temperatures nearest the chamber walls are similar between the cases, consistent with the low temperature side of the mass-temperature distribution. Similar behavior is observed when viewed from the side in Figures 4(c)-4(d).

Figure 5(a) shows the total rate of heat release due to end-gas auto-ignition decrease with increasing spark advance, consistent with the overall heat release rate trends presented in Figure 2(b). Normalizing the results of Figure 5(a) by the total end-gas mass undergoing auto-ignition gives the specific heat release rate of the end-gas, presented in Figure 5(b). The results show that the end-gas of the latest spark timing case has $20 \%$ higher specific heat release rate than the earliest spark timing case. Figure 5(c) shows the integrated mass above a given specific heat release rate, generated at $10^{\circ}$ aTDC, which is in proximity to where the overall peak end-gas heat release rate occurs. The integration is performed by sorting the domain by the specific rate of heat release of each cell from high to low value, calculating the mass of the associated cell, and then summing the masses while moving from high to low specific rate of heat release. A higher value on the plot indicates a greater mass above a given specific heat release rate, while the cumulative mass at 0 specific rate of heat release is the total mass of the end-gas.

Considered together, Figures 3-5 show that the increased time available for flame propagation in the earliest spark timing case allows the flame front to preferentially consume a larger portion of the hottest and most reactive mass near the center of the combustion chamber compared to the later spark timing cases. The remaining mass present at the time of end-gas auto-ignition in the earliest spark timing case is then closer to the chamber walls, colder, and less reactive compared to the late timing case. The results indicate that both the overall mass remaining in the end-gas at auto-ignition (not consumed by flame propagation) as well as the thermal and compositional distribution of the end-gas contribute to the decrease in peak heat release rate with advancing spark timing.

The larger implication of the conclusions of this study point toward methods to further control engine 
heat release rates during mixed modes of combustion. The results indicate that any method which intentionally or unintentionally affects the thermal stratification near the wall will show a corresponding change in the heat release rate. For example, changing the coolant temperature could change the peak heat release even with fixed spark timing during SACI engine operation. While this study used a centrally mounted spark plug configuration, similar trends can be expected in other hardware configurations where the flame would consume the most reactive portions of the charge, leaving less reactive end-gas to autoignition.

\section{Summary and Conclusions}

This work investigates the variations in the peak rate of heat release observed at a constant phasing during SACI combustion when the fraction of flame and auto-ignition heat release were adjusted through changes in spark timing and $T_{\text {IVC. }}$. Simulations conducted with the 3D CFD code KIVA-3V and a newly derived SACI model successfully reproduced experimental trends, where the fraction of flame propagation increased as spark timing was advanced and $T_{\mathrm{IVC}}$ was decreased. The simulation predictions showed that in the earliest spark timing cases the additional time available for flame propagation provided additional compression heating to overcome differences in $T_{\mathrm{IVC}}$ and allowed all 3 cases to reach the mean end-gas temperatures required to initiate end-gas auto-ignition at a similar crank angle.

While some of the reduction in the end-gas rate of heat release was associated with the reduced end-gas mass available for auto-ignition as the flame consumed more of the charge, the specific end-gas heat release rates also differed between the predicted cases. Detailed analysis of the end-gas state prior to auto-ignition showed that not only did the total end-gas mass decrease with spark timing advance, but that the thermal and equivalence ratio distributions also shift to lower peak values. This shift leads to a reduction in the specific energy release rate at the early spark timing, which has less mass in regions of high heat release rate. The observed reduction in overall heat release rate with increasing spark advance therefore results from the reduction in end-gas mass available at auto-ignition, as well as a shift in the distribution of temperatures and equivalence ratios toward lower reactivities.

This is the first study to quantify the detailed chemical and physical mechanisms describing the successful application of SACI to independently control phasing and heat release rates in engines. The results provide the basis for understanding how compositional and thermal stratification can be used to actively control and improve SACI engine operation. 


\section{Acknowledgements}

This work was supported by: A University Consortium on Efficient and Clean High Pressure Lean Burn (HPLB) Engines, Department of Energy Contract DE-EE0000203. The authors thank Drs. Aris Babajimopoulos and Janardhan Kodavasal for their technical advice with KIVA, and Prof. J.Y. Chen for the use of the isooctane mechanism. 


\section{References}

[1] S. Onishi, S. H. Jo, K. Shoda, P. D. Jo, S. Kato, SAE Paper 790501 (1979).

[2] R. H. Thring, SAE Paper 892068 (1989).

[3] M. Christensen, B. Johansson, P. Einewall, SAE Paper 972874 (1997).

[4] F. Zhao, T. Asmus, D. Assanis, J. Dec, J. Eng, P. Najt, Inc., Warrendale, PA (2003).

[5] J. E. Dec, Y. Yang, SAE International Journal of Engines 3 (2010) 750-767.

[6] J.-O. Olsson, P. Tunestål, B. Johansson, S. Fiveland, R. Agama, M. Willi, D. Assanis, SAE Paper 2002-01-0111 (2002).

[7] A. Cairns, H. Blaxill, SAE Paper 2005-01-0133 (2005).

[8] B. Zigler, P. Keros, K. Helleberg, M. Fatouraie, D. Assanis, M. Wooldridge, International Journal of Engine Research 12 (2011) 353-375.

[9] J. B. Martz, G. A. Lavoie, H. G. Im, R. J. Middleton, A. Babajimopoulos, D. N. Assanis, Combustion and Flame 159 (2012) $2077-2086$.

[10] L. M. Olesky, J. B. Martz, G. A. Lavoie, J. Vavra, D. N. Assanis, A. Babajimopoulos, Applied Energy 105 (2013) $407-417$.

[11] H. Yun, N. Wermuth, P. Najt, SAE International Journal of Engines 3 (2010) 681-699.

[12] A. A. Amsden, KIVA-3V: A block-structured KIVA program for engines with vertical or canted valves, Technical Report, Los Alamos National Lab., NM (United States), 1997.

[13] C. Meneveau, T. Poinsot, Combustion and Flame 86 (1991) 311-332.

[14] T. Baritaud, J. Duglos, A. Fusco, in: Symposium (International) on Combustion, volume 26, Elsevier, pp. 2627-2635.

[15] A. Babajimopoulos, D. Assanis, D. Flowers, S. Aceves, R. Hessel, International Journal of Engine Research 6 (2005) $497-$ 512 .

[16] J. B. Martz, Simulation and Model Development for Auto-Ignition and Reaction Front Propagation in Low-Temperature High-Pressure Lean-Burn Engines, Ph.D. thesis, The University of Michigan, 2010.

[17] R. J. Middleton, Simulation of Spark Assisted Compression Ignition Combustion Under EGR Dilute Engine Operating Conditions, Ph.D. thesis, The University of Michigan, 2014.

[18] Y. F. Tham, F. Bisetti, J. Y. Chen, Journal of Engineering for Gas Turbines and Power 130 (2008) 042804.

[19] H. J. Curran, P. Gaffuri, W. Pitz, C. Westbrook, Combustion and Flame 129 (2002) 253-280.

[20] Z. Tan, R. D. Reitz, Combustion and Flame 145 (2006) 1-15.

[21] P. Boudier, S. Henriot, T. Poinsot, T. Baritaud, in: Symposium (International) on Combustion, volume 24, Elsevier, pp. $503-510$.

[22] J. Martz, R. Middleton, G. Lavoie, A. Babajimopoulos, D. Assanis, Combustion and Flame 158 (2011) 1089 - 1096.

[23] R. J. Middleton, J. B. Martz, G. A. Lavoie, A. Babajimopoulos, D. N. Assanis, Combustion and Flame 159 (2012) $3146-3157$.

[24] L. K. Olesky, An Experimental Investigation of the Burn Rates of Naturally Aspirated Spark Assisted Compression Ignition Combustion in a Single Cylinder Engine with Negative Valve Overlap, Ph.D. thesis, The University of Michigan, 2013.

[25] C. Chryssakis, D. N. Assanis, Atomization and Sprays 18 (2008).

[26] C. A. Chryssakis, D. N. Assanis, J.-K. Lee, K. Nishida (2003).

[27] E. Ortiz-Soto, Combustion Modeling of Spark Assisted Compression Ignition for Experimental Analysis and Engine System Simulations, Ph.D. thesis, The University of Michigan, 2013. 
[28] A. Omrane, G. Juhlin, M. Aldén, G. Josefsson, J. Engström, T. Benham, SAE Paper 2004-01-0609 (2004).

[29] X. He, M. Donovan, B. Zigler, T. Palmer, S. Walton, M. Wooldridge, A. Atreya, Combustion and Flame 142 (2005) $266-275$. 


\section{Tables}

Table 1: Engine and Mesh Geometry

\begin{tabular}{rrr}
\hline Parameter & Value & Unit \\
\hline Displacement & 550 & $\mathrm{~cm}^{3}$ \\
Bore & 86.0 & $\mathrm{~mm}$ \\
Stroke & 94.6 & $\mathrm{~mm}$ \\
Con. Rod Length & 156.5 & $\mathrm{~mm}$ \\
Compression Ratio & $12.4: 1$ & \\
\hline
\end{tabular}

Table 2: SACI operating conditions studied, $2000 \mathrm{rpm}$

\begin{tabular}{rrrrrrrr}
\hline $\begin{array}{r}\text { Spark Timing } \\
{ }^{\circ} \text { bTDC }\end{array}$ & $\begin{array}{r}\text { NVO } \\
{ }^{\circ} \mathrm{CA}\end{array}$ & $\begin{array}{r}\text { Phi } \\
\text { Exp }\end{array}$ & $\begin{array}{r}\text { Phi } \\
\text { Model }\end{array}$ & $\begin{array}{r}\text { iEGR } \\
\%\end{array}$ & $\begin{array}{r}\text { eEGR } \\
\%\end{array}$ & $\begin{array}{r}\text { EGR } \\
\%\end{array}$ & $\begin{array}{r}T_{\text {intake }} \\
\text { Model }[\mathrm{K}]\end{array}$ \\
\hline 44 & 114 & 0.96 & 0.968 & 22.8 & 17.0 & 39.8 & 318 \\
34 & 128 & 0.97 & 0.966 & 25.5 & 14.4 & 39.9 & 326 \\
25 & 136 & 0.98 & 0.996 & 27.4 & 11.9 & 39.3 & 333 \\
\hline
\end{tabular}

\section{Figures}

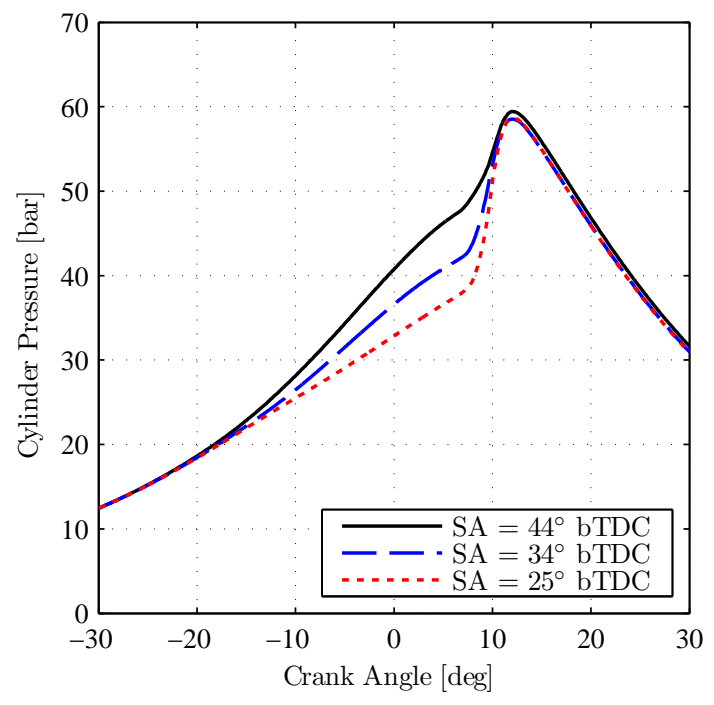

(a) Simulation Predictions

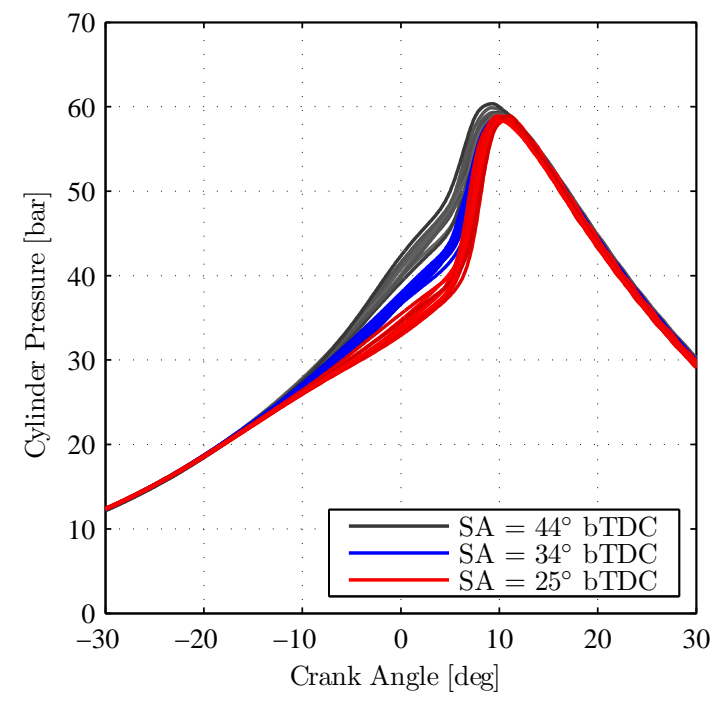

(b) Select Experimental Cycles

Figure 1: Cylinder Pressure vs. Crank Angle for SACI operation, where spark advance and NVO duration are simultaneously adjusted to maintain constant combustion phasing (CA50). 


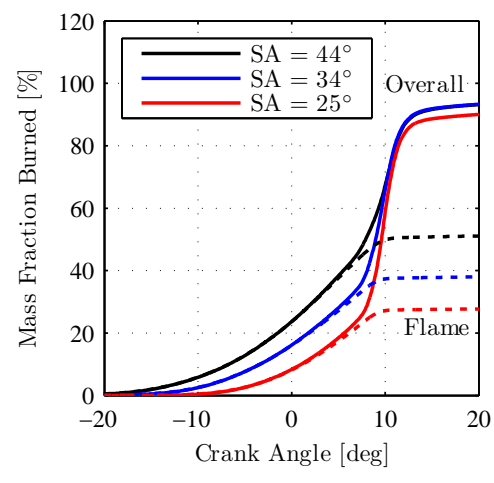

(a)

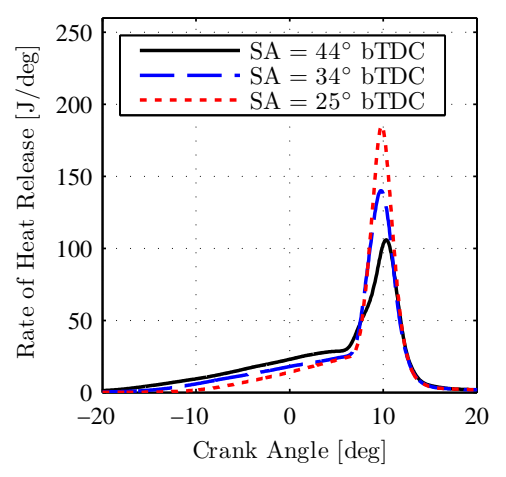

(b)

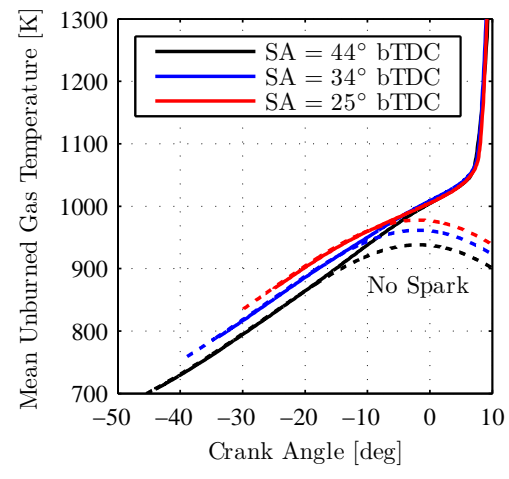

(c)

Figure 2: Model predicted mass fraction burned profiles, which shows that advancing spark timing from $25^{\circ} \mathrm{bTDC}$ to $44^{\circ} \mathrm{bTDC}$ increases the fraction of flame based heat release 2(a) and reduces the peak rate of heat release by $43 \% 2$ (b). The predicted mean unburned gas temperatures in 2(c) are initially lower for cases with the greatest spark advance, converging toward a common path prior to the onset of end-gas auto-ignition.

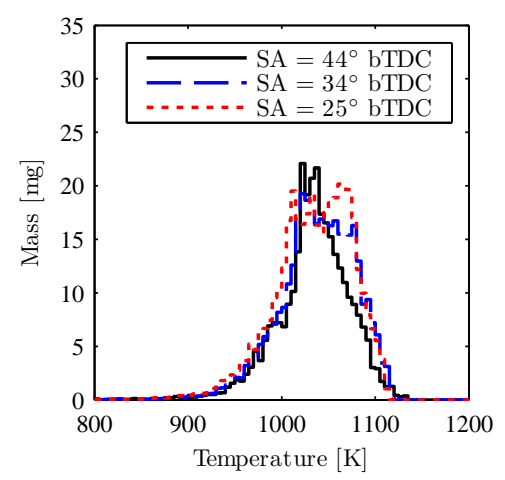

(a) Temperature

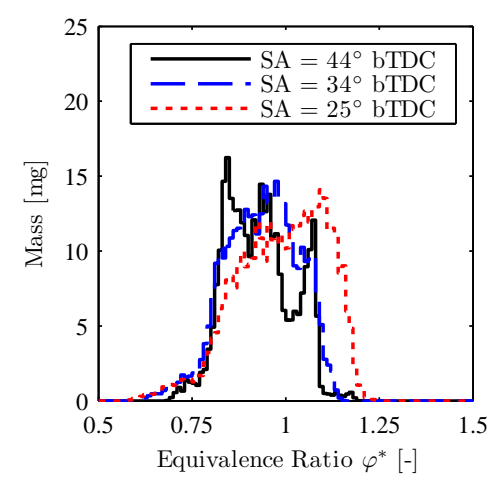

(b) Composition

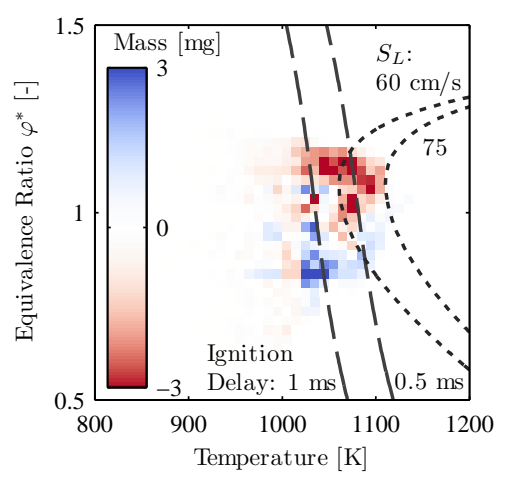

(c) Difference

Figure 3: Unburned gas state mass distributions at $5^{\circ}$ aTDC, immediately prior to autoignition. Figure 3(a) generated with $5 \mathrm{~K}$ temperature bins, Figure 3(b) with $0.01 \varphi^{*}$ bins. Figure 3(c) presents the difference between the $44^{\circ}$ bTDC and $25^{\circ}$ cases using $10 \mathrm{~K}$ and $0.025 \mathrm{bins}$, where red/negative values indicate more mass in the $25^{\circ} \mathrm{bTDC}$ case. The $25^{\circ}$ bTDC timing case with the highest peak rate of heat release has more mass at high temperatures and rich equivalence ratios than the earlier timing cases, corresponding to lower ignition delay and higher $S_{L}$. 


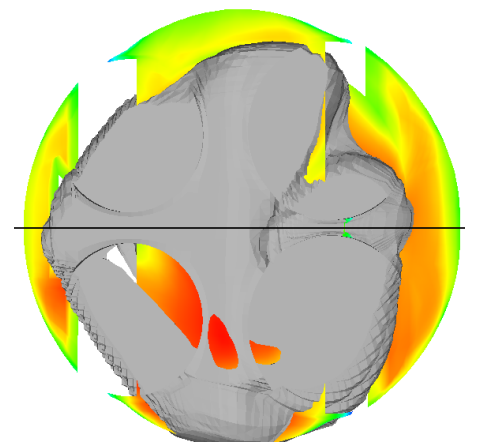

(a) $\mathrm{SA}=44^{\circ} \mathrm{bTDC}$

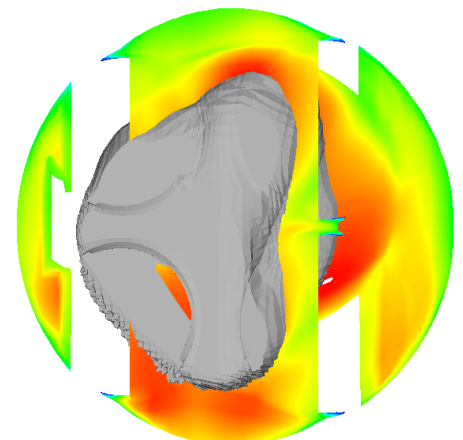

(b) $\mathrm{SA}=25^{\circ} \mathrm{bTDC}$

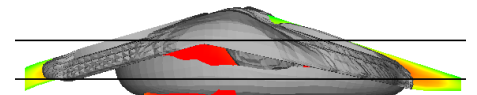

(c) $\mathrm{SA}=44^{\circ} \mathrm{bTDC}$

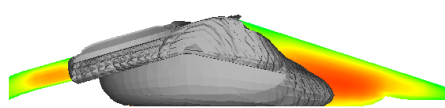

(d) $\mathrm{SA}=25^{\circ} \mathrm{bTDC}$

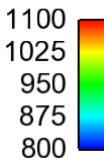

(e) $T_{u}$

Figure 4: Unburned gas temperature and flame front location at $5^{\circ}$ aTDC. Viewed from above in 4(a) and 4(b), with clip planes near the bottom and top of the pent roof combustion chamber as indicated by lines in 4(c). Viewed from the side in 4(c) and 4(d), with clip plane through combustion chamber center as indicated by the line in 4(a). Flame location given by gray iso-surface of $\Sigma>1 \mathrm{~cm}^{-1}$.

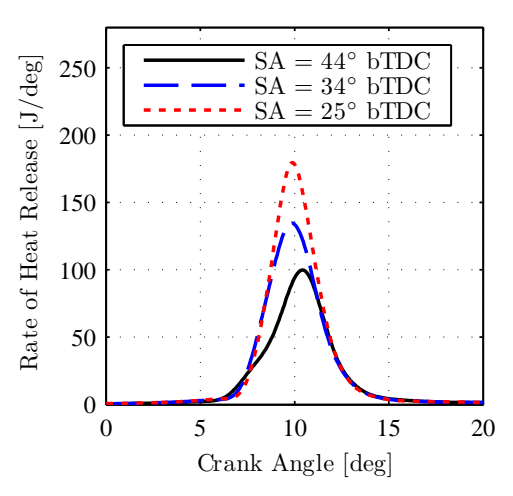

(a) Extensive

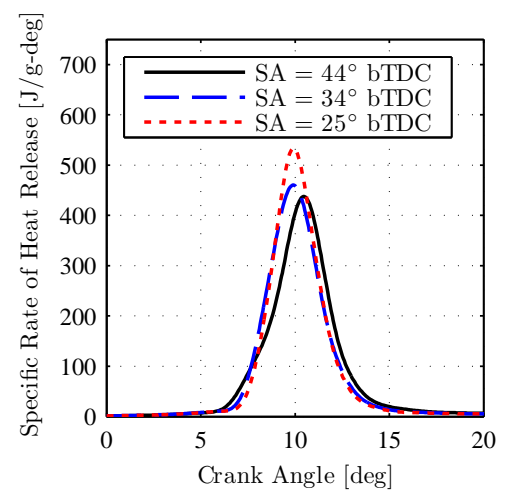

(b) Intensive

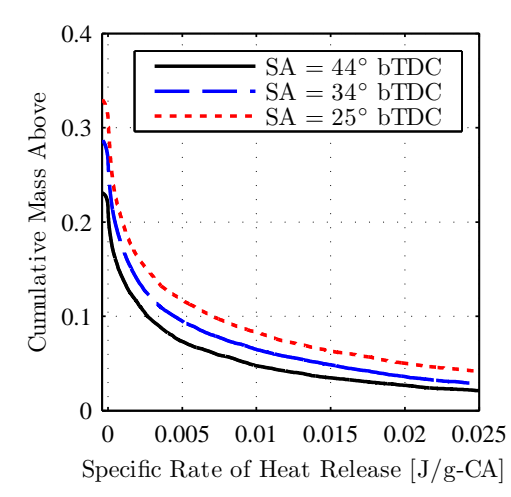

(c) Integral

Figure 5: End gas contribution to the overall heat release rate shows decreasing heat release with increasing spark advance, on both an overall 5(a) and a per mass 5(b) basis. At the time of the peak heat release rate, the latest spark timing case has more mass at high heat release rates than the earlier timing cases 5(c). 


\section{List of Tables}

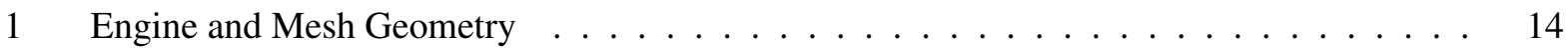

2 SACI operating conditions studied, $2000 \mathrm{rpm} \ldots \ldots \ldots \ldots \ldots$

\section{List of Figures}

1 Cylinder Pressure vs. Crank Angle for SACI operation, where spark advance and NVO duration are simultaneously adjusted to maintain constant combustion phasing (CA50). . .

2 Model predicted mass fraction burned profiles, which shows that advancing spark timing from $25^{\circ} \mathrm{bTDC}$ to $44^{\circ} \mathrm{bTDC}$ increases the fraction of flame based heat release 2(a) and reduces the peak rate of heat release by $43 \% 2(\mathrm{~b})$. The predicted mean unburned gas temperatures in 2(c) are initially lower for cases with the greatest spark advance, converging toward a common path prior to the onset of end-gas auto-ignition.

3 Unburned gas state mass distributions at $5^{\circ}$ aTDC, immediately prior to autoignition. Figure 3(a) generated with $5 \mathrm{~K}$ temperature bins, Figure 3(b) with $0.01 \varphi^{*}$ bins. Figure 3(c) presents the difference between the $44^{\circ}$ bTDC and $25^{\circ}$ cases using $10 \mathrm{~K}$ and 0.025 bins, where red/negative values indicate more mass in the $25^{\circ} \mathrm{bTDC}$ case. The $25^{\circ} \mathrm{bTDC}$ timing case with the highest peak rate of heat release has more mass at high temperatures and rich equivalence ratios than the earlier timing cases, corresponding to lower ignition delay and

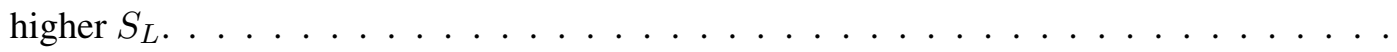

4 Unburned gas temperature and flame front location at $5^{\circ}$ aTDC. Viewed from above in 4(a) and 4(b), with clip planes near the bottom and top of the pent roof combustion chamber as indicated by lines in 4(c). Viewed from the side in 4(c) and 4(d), with clip plane through combustion chamber center as indicated by the line in 4(a). Flame location given by gray

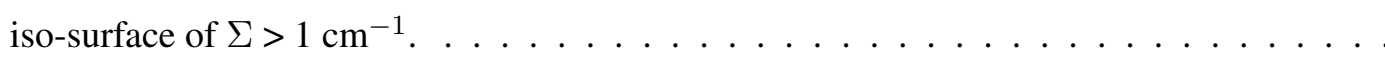

5 End gas contribution to the overall heat release rate shows decreasing heat release with increasing spark advance, on both an overall 5(a) and a per mass 5(b) basis. At the time of the peak heat release rate, the latest spark timing case has more mass at high heat release rates than the earlier timing cases $5(\mathrm{c}) \ldots \ldots \ldots \ldots \ldots \ldots$ 